\title{
Pulmonary Blood Volume in Mitral Stenosis
}

\author{
SUJOY B. ROY,* M.B., F.R.C.P. ; PREM BHARDWAJ, $\dagger$ M.D. ; M. L. BHATIA, $\ddagger$ M.D., D.M.
}

Brit. med. F., 1965, 2, 1466-1469

Various haemodynamic parameters in patients with mitral stenosis have been extensively studied but only a few measurements of the pulmonary blood volume are available (Milnor et al., 1960 ; Dock et al., 1961 ; McGaff et al., 1963 ; Schreiner et al., 1963 ; Yu et al., 1963). Furthermore, no worker has correlated the pulmonary symptoms of patients with mitral stenosis to their pulmonary blood volume. The pulmonary blood volume estimated in 33 patients with mitral valve disease and 15 normal healthy volunteers forms the basis of this report. This study was undertaken to delineate the range of pulmonary blood volume in normal persons and to correlate pulmonary symptoms to pulmonary blood volume and other haemodynamic parameters in patients with mitral valve disease.

\section{Material and Method:}

Clinical material consisted of 15 normal volunteers (14 males, one female), healthy in all respects, with an average age of 23 (range 17-33 years), and 33 patients with rheumatic heart disease ( 23 males, 10 females), with an average age of 27 (range 11-45 years). Twenty-nine of these patients had pure or predominant mitral stenosis; functionally five were in class I, 11 in class II, and 13 in class III, according to New York Heart Association (1953) classification. The remaining four patients had predominant mitral regurgitation; three were in class I and the fourth in class II. Twenty-eight patients had normal sinus rhythm, and five $(15 \%)$ with mitral stenosis had atrial fibrillation. No patient was in congestive heart failure at the time of study, though of the 29 patients with mitral stenosis $10(34 \%)$ gave a past history of cardiac decompensation, $11(38 \%)$ of one or more bouts of haemoptysis, and $6(21 \%)$ of paroxysmal nocturnal dyspnoea.

Right heart catheterization was done in the usual manner, and the left heart was catheterized by Brockenbrough's transseptal technique (Brockenbrough and Braunwald, 1960). Details of the method as practised in this laboratory have already been * Professor of Cardiology, All India Institute of Medical Sciences, New
Delhi, India.
+ Teaching Fellow in Medicine, All India Institute of Medical Sciences,
New Delhi, India.
$\ddagger$ Assistant Professor of Cardiology, All India Institute of Medical
Sciences, New Delhi, India. reported (Roy et al., 1963). The right femoral artery was cannulated for arterial blood-pressure and dye curves. Critically damped intracardiac and femoral arterial pressures were recorded through Statham P23 Db strain-gauge manometers on a fourchannel single-gun photographic recording system. Baseline for all pressure measurements was taken as half the chest thickness at the second costal cartilage with the patient supine (Roy et al., 1957). Dye-dilution curves were inscribed directly on a polyviso channel after sequential injection of $25 \mathrm{mg}$. of $0.5 \%$ indigo-carmine dye into the pulmonary artery and the left atrium, and collecting the dye at the right femoral artery through a continuous recording densitometer (Colson).

The cardiac output and the pulmonary-artery-to-femoralartery and the left-atrium-to-femoral-artery mean circulation times were calculated from the dilution curves as described by Hamilton et al. (1932). The pulmonary-artery-to-femoralartery volume was calculated as the product of the cardiac output and the pulmonary-artery-to-femoral-artery mean circulation time. Similarly, the left-atrium-to-femoral-artery volume was obtained as a product of cardiac output and the left-atrium-to-femoral-artery mean circulation time. Pulmonary blood volume was obtained as the difference of pulmonary-artery-to-femoral-artery volume and leftatrium-to-femoral-artery volume. The pulmonary vascular compliance was estimated as a ratio of pulmonary blood volume and mean intravascular distending pressure; the latter was obtained by averaging the sum of the left atrial and pulmonary arterial mean pressures.

\section{Results}

Pulmonary Symptoms and Pulmonary Blood Volume.-As shown in Fig. 1 and in the Table, the pulmonary blood volume in 15 normal volunteers ranged between 145 and $310 \mathrm{ml} . / \mathrm{m}^{2}$, with an average of $211 \mathrm{ml} . / \mathrm{m}^{2}$ The four patients with predominant mitral regurgitation had a slightly higher average pulmonary blood volume of $266 \mathrm{ml} . / \mathrm{m}^{2}$ It is also apparent from Fig. 1 that as the exertional dyspnoea increased the pulmonary blood volume proportionately increased. Thus patients with mild dyspnoea (class 1 ) had an average pulmonary blood volume of only $370 \mathrm{ml} . / \mathrm{m}^{2}$, while those with severe (class III) dyspnoea had $437 \mathrm{ml} . / \mathrm{m}^{2}{ }^{2}$ Similarly, the average

Pulmonary Blood Volume and Haemodynamic Parameters in Mitral Stenosis

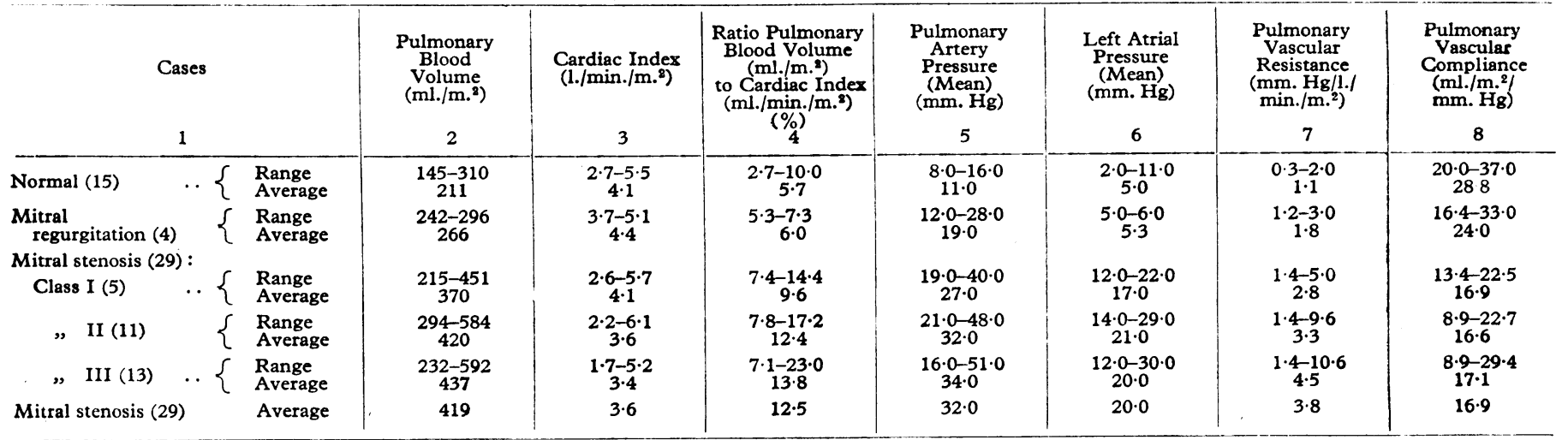


pulmonary blood volume of patients with haemoptysis was 450 $\mathrm{ml} . / \mathrm{m} .^{2}$; in patients with paroxysmal nocturnal dyspnoea it was $478 \mathrm{ml} . / \mathrm{m}^{2}$

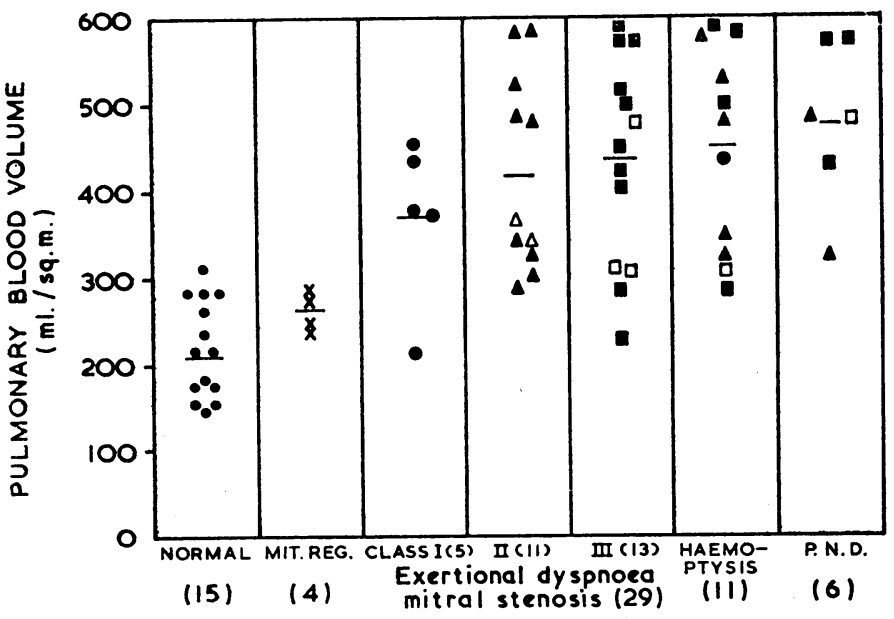

Fig. 1.-Distribution of pulmonary blood volume in millilitres per square metre in 48 persons grouped according to diagnosis. Mitral stenosis metre in 48 persons grouped according to diagnosis. Mitral stenosis patients are further subdivided into their functional classes in panels 3,4 , and 5 . The last two panels show cases of mitral stenosis with
symptoms of haemoptysis or/and paroxysmal nocturnal dyspnoea. Open symptoms of haemoptysis or/and paroxysmal nocturnal dyspnoea. Open
signs denote atrial fibrillation; closed signs are for patients with normal signs denote atrial fibrillation; closed signs are for patients with normal
sinus rhythm. The bar across each panel represents average value.

Pulmonary Symptoms and Pulmonary Dynamics.-The average cardiac index (expressed at litres per minute per square metre) of the 15 normal volunteers was 4.1, of mitral regurgitation patients was 4.4 , of mitral stenosis patients class I was 4.1, class II 3.6, and class III 3.4, as shown in the Table. There was no apparent relation between the pulmonary blood volume and the cardiac index. The pulmonary-blood-volume/ cardiac-index ratio (Fig. 2) appeared to increase as the pulmonary symptoms of mitral stenosis patients became more pronounced. The ratio was 9.6 for patients of class I, whereas it was 13.8 for class III patients. As the exertional dyspnoea increased, the pulmonary arterial mean pressure and the pulmonary vascular resistance also increased (see Table). Pulmonary vascular compliance, on the other hand, did not show significant difference in the three groups.

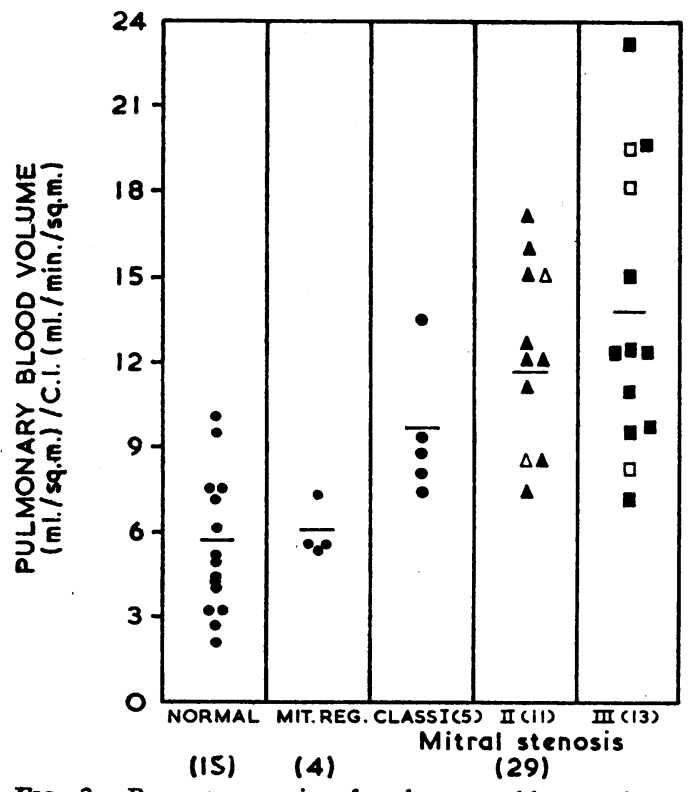

Fig. 2.-Percentage ratio of pulmonary blood volume (ml. $/ \mathrm{m.}^{2}$ ) to cardiac index ( $\mathrm{ml} . / \mathrm{min} . / \mathrm{m}^{2}$ ) in 48 persons grouped according to diagnosis. Mitral stenosis patients are further subdivided into their functional classes in the hast three panels. Open signs denote atrial fibrillation and three panels. Open signs denote atrial fibrillation and closed signs are for patients with normal sinus
rhythm. The bar across each panel represents average value.
Pulmonary Blood Volume and Left Atrial Mean Pressure.The left atrial mean pressure of the 29 patients with mitral stenosis was mildly elevated (12 to $19 \mathrm{~mm}$. $\mathrm{Hg}$ ) in 14 patients, moderately elevated (20 to $24 \mathrm{~mm}$. $\mathrm{Hg}$ ) in nine, and severely elevated (over $24 \mathrm{~mm}$. $\mathrm{Hg}$ ) in six patients (Fig. 3). Average pulmonary blood volume increased as the left atrial pressure increased up to $27 \mathrm{~mm}$. $\mathrm{Hg}$, but then it started decreasing. The average pulmonary blood volume in the mild group was $374 \mathrm{ml} . / \mathrm{m}^{2}$, in the moderate group $478 \mathrm{ml} . / \mathrm{m}^{2}$, and in the severe group $436 \mathrm{ml} . / \mathrm{m}^{2}$

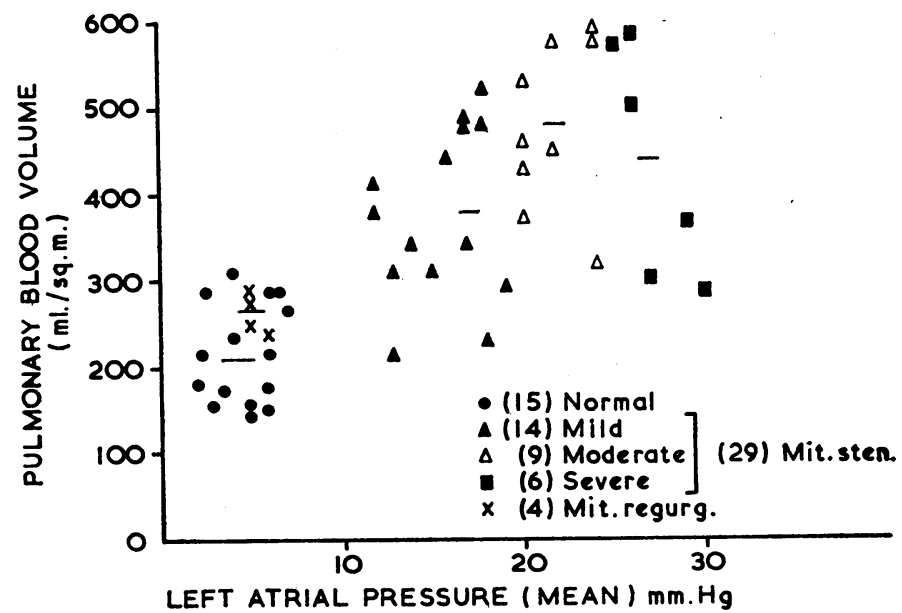

FIG. 3.-Relating pulmonary blood volume to left atrial mean pressure in 48 persons grouped according to diagnosis. Left atrial mean pressure is graded as normal when below $12 \mathrm{~mm}$. Hg, slight when 12-19 mm. $\mathrm{Hg}$, moderate when $20-24 \mathrm{~mm}$. $\mathrm{Hg}$, and severe when above $24 \mathrm{~mm}$. $\mathrm{Hg}_{\mathrm{g}}$ The horizontal bar in each group denotes average value.

Pulmonary Blood Volume and Pulmonary Arterial Mean Pressure.-There were 11 patients with mildly elevated pulmonary arterial mean pressure (below $30 \mathrm{~mm} . \mathrm{Hg}$ ), 17 with moderately elevated pressure (30 to $49 \mathrm{~mm}$. $\mathrm{Hg}$ ), and only one in the severe group (over $49 \mathrm{~mm}$. $\mathrm{Hg}$ ). As shown in Fig. 4, though there was a wide scatter, pulmonary blood volume increased as the pulmonary arterial pressure increased. Thus the mild group had an average pulmonary blood volume of $384 \mathrm{ml} . / \mathrm{m}^{2}{ }^{2}$ against the moderate of $437 \mathrm{ml} . / \mathrm{m}^{2}{ }^{2}$ The single patient in the severe group had a pulmonary blood volume of $502 \mathrm{ml} . / \mathrm{m}^{2}$ The average pulmonary blood volume of the three patients with mitral regurgitation and normal pulmonary arterial pressure was $264 \mathrm{ml} . / \mathrm{m}^{2}$; the fourth mitral regurgitation patient had mild pulmonary hypertension and the pulmonary blood volume was $270 \mathrm{ml} / \mathrm{m}^{2}$

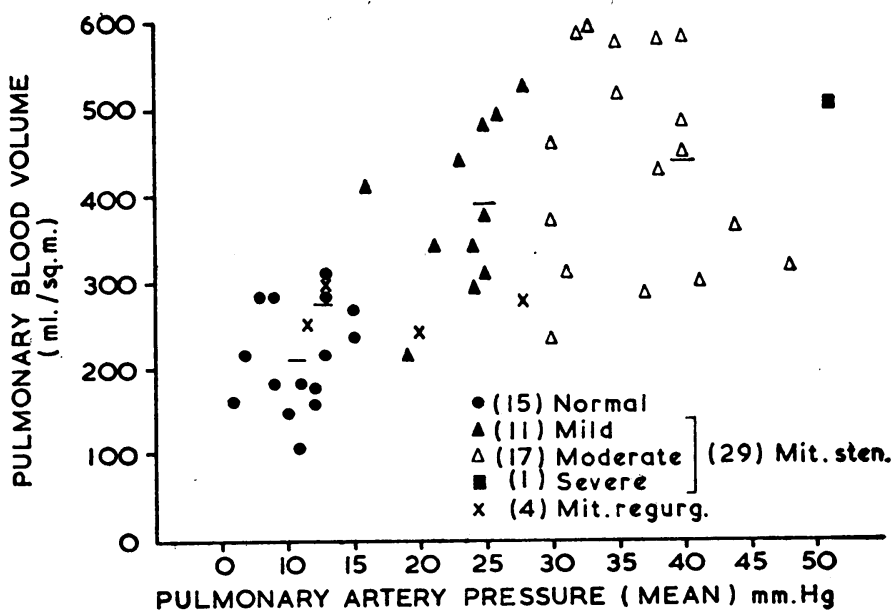

Fig. 4.-Relating pulmonary blood volume to pulmonary arterial mean pressure in 48 persons grouped according to diagnosis. Pulmonary arterial mean pressure is graded as normal when below $15 \mathrm{~mm}$. Hg, slight when $15-29 \mathrm{~mm}$. Hg, moderate when $30-49 \mathrm{~mm}$. $\mathrm{Hg}$, and severe when more than $49 \mathrm{~mm}$. Hg. The bar in each group denotes average value. 
Pulmonary Blood Volume and Pulmonary Vascular Resistance and Compliance.-The pulmonary vascular resistance in patients with mitral stenosis was normal (less than $2.1 \mathrm{~mm}$. $\left.\mathrm{Hg} / 1 . / \mathrm{min} . / \mathrm{m}^{2}\right)$ in nine, mild $(2.1$ to 3.9$)$ in 11 , moderate (4 to 7 ) in six, and markedly elevated (more than 7 ) in three. It is to be noted that the pulmonary blood volume decreased as the pulmonary vascular resistance increased (Fig. 5). Thus patients with normal pulmonary vascular resistance had an average pulmonary blood volume of $441 \mathrm{ml} . / \mathrm{m}^{2}$, whereas the

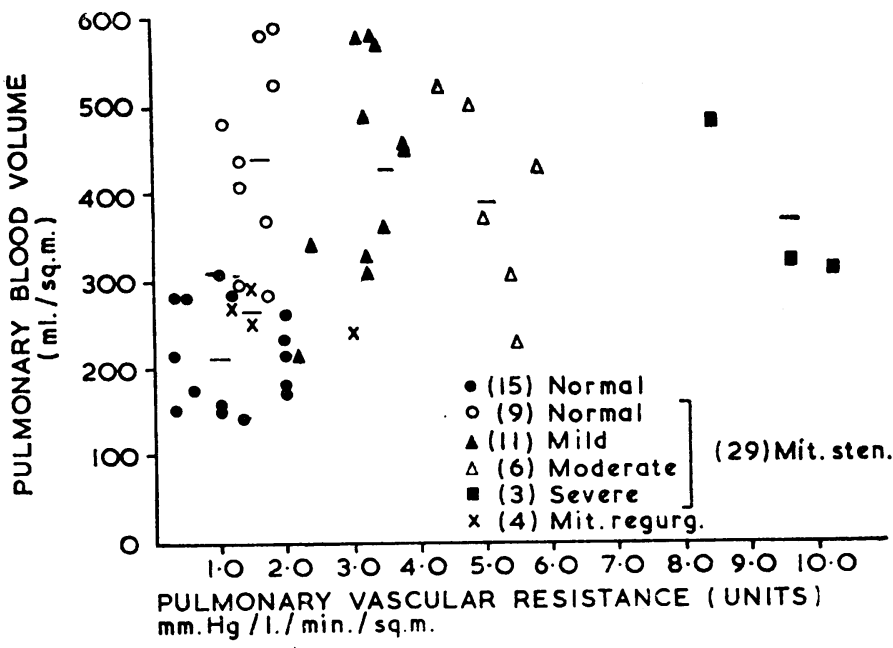

Fig. 5.-Relation of pulmonary blood volume to pulmonary vascular resistance in 48 persons grouped according to diagnosis. Pulmonary vascular resistance is graded as normal when below $2.1 \mathrm{~mm}$. Hg. $/ 1 . / \mathrm{min}$./ vascular resistance is graded as normal when below $2.1 \mathrm{~mm}$. Hg./ $/ . / \mathrm{min} . /$
$\mathrm{m}^{2}$, slight when $2.1-3.9$, moderate when $4-7$, and severe when more than $7 \mathrm{~mm}$. $\mathrm{Hg} / 1 . / \mathrm{min} . / \mathrm{m}^{2}$. The bar in each group denotes average value.

average pulmonary blood volume was $393 \mathrm{ml} . / \mathrm{m} .^{2}$ in patients with moderately increased pulmonary vascular resistance. The pulmonary vascular compliance was $28.8 \mathrm{ml} . / \mathrm{m} .{ }^{2} / \mathrm{mm}$. $\mathrm{Hg}$ in 15 normal subjects and 16.9 in the 29 patients with mitral stenosis. As shown in the Table, column 8 , pulmonary vascular compliance could not be related to either pulmonary blood volume or pulmonary symptoms.

\section{Discussion}

Pulmonary blood volume of $211 \mathrm{ml} . / \mathrm{m}^{2}$ as recorded in 15 normal persons is comparable to the values estimated in four haemodynamically normal subjects by Dock et al. (1961), and five by McGaff et al. (1963); their values were 246 and 230 $\mathrm{ml} . / \mathrm{m}^{2}$ respectively. However, none of the nine subjects was truly normal, as they either had cardiac murmurs or were post-operative mitral stenosis patients. Determination of pulmonary blood volume as $515 \mathrm{ml} . / \mathrm{m}^{2}$ by Eich et al. (1961), with external scintillating counter, was probably too high, as the method also included a considerable amount of right and left heart blood volume. From this study it is possible to record the range of pulmonary blood volume of normal persons at 150 to $300 \mathrm{ml} . / \mathrm{m}^{2}$, and any value outside this range may be regarded as abnormal.

Also it is apparent from the present data that the pulmonary blood volume of patients with mitral stenosis is almost twice that of normal subjects. Dock et al. (1961) found an average value of $335 \mathrm{ml} . / \mathrm{m}^{2}$ in mitral stenosis patients. As severe pulmonary vascular resistance decreases the pulmonary blood volume, this lower value was due to inclusion in their study of more than $50 \%$ of the patients with severe pulmonary vascular resistance (more than 500 dynes $/ \mathrm{sec} . / \mathrm{cm}^{-5}$ ). McGaff et al. found an average value of $359 \mathrm{ml} . / \mathrm{m}^{2}$ in 34 patients with rheumatic heart disease. Though they stated that patients with mitral stenosis tended to have higher pulmonary blood volume, detailed data were not given. Yu's group (Yu et al., 1963;
Schreiner et al., 1963) studied eight patients with predominant mitral stenosis, and the calculated average pulmonary blood volume was $266 \mathrm{ml} . / \mathrm{m}^{2}$ As the pulmonary vascular resistance was not given in all the cases, their data cannot be compared. Similarly, pulmonary blood volume of $571 \mathrm{ml} . / \mathrm{m} .{ }^{2}$ recorded by Lagerlöff et al. (1959) also is not comparable, as the left atrial volume was estimated radiologically.

It is of interest to observe the relation of pulmonary blood volume to such pulmonary symptoms as exertional dyspnoea, haemoptysis, and paroxysmal nocturnal dyspnoea. That patients with mitral stenosis get progressively breathless as the pulmonary blood volume increases was documented by the three functional groups. Also of importance was the fact that the average pulmonary blood volume of the six patients with paroxysmal nocturnal dyspnoea was $478 \mathrm{ml} . / \mathrm{m}^{2}$, while the remaining 23 patients had an average blood volume of 404 $\mathrm{ml} . / \mathrm{m}^{2}$ Similarly, the 11 patients with haemoptysis had a higher pulmonary blood volume $\left(450 \mathrm{ml} . / \mathrm{m}^{2}\right)$ than the remaining 18 patients $\left(400 \mathrm{ml} . / \mathrm{m}^{2}\right)$ Of greater interest, perhaps, is the fact that two patients with grade III dyspnoea had slight elevation of pulmonary arterial $(30$ and $35 \mathrm{~mm}$. $\mathrm{Hg}$ ) and left atrial mean (20 and $18 \mathrm{~mm}$. $\mathrm{Hg}$ ) pressures, but had a markedly elevated pulmonary blood volume of 457 and 520 $\mathrm{ml} . / \mathrm{m}^{2}$ respectively. As no investigator has attempted to correlate pulmonary symptoms to pulmonary blood volume the present data cannot be critically reviewed.

When the pulmonary symptoms were related to pulmonaryblood-volume/cardiac-index ratio, the value proportionately increased as the exertional dyspnoea increased. Similarly, exertional dyspnoea as a group also could be related to the increase of pulmonary arterial and pulmonary vascular resistance, though it could not be related to the pulmonary vascular compliance. Pulmonary blood volume also could be directly related to pulmonary arterial mean pressure in that as the pressure increased the blood volume increased too. The pulmonary blood volume similarly increased with the increase of left atrial pressure, but only up to $27 \mathrm{~mm}$. $\mathrm{Hg}$, after which it tended to fall. However, it is to be noted that only one patient had marked pulmonary arterial hypertension; had there been more such patients the results might have been different and might have simulated the left atrial hypertension pattern. Similar observations have been made by Milnor et al. (1960) and McGaff et al. (1963). Unlike McGaff et al. (1963), we could not relate pulmonary blood volume to cardiac index. Our observations support the findings of Dock et al. (1961). Pulmonary vascular resistance could be inversely related to pulmonary blood volume; the resistance increased as the blood volume decreased. Though the pulmonary vascular compliance of normal volunteers was much higher than that of patients with mitral stenosis, no direct relation could be established between pulmonary vascular compliance and pulmonary blood volume. This is understandable, because pulmonary vascular compliance was calculated as a ratio of pulmonary blood volume to the pulmonary distending pressure, obtained by averaging the left atrial and pulmonary arterial mean pressures.

Arnott (1963) has rightly pointed out that the syndrome of mitral stenosis is primarily reflected as a pulmonary disorder. Hence most of the haemodynamic measurements pertain to the pulmonary circuit. It would appear from the present study that estimation of pulmonary blood volume is an additional useful parameter and may, in part, explain the discrepancy seen in certain patients between the severity of their pulmonary symptoms and the degree of haemodynamic derangement.

\section{Summary}

Data on the pulmonary blood volume and related haemodynamic parameters, as obtained by right and left heart catheterization in 15 normal healthy volunteers, four patients with mitral regurgitation, and 29 patients with mitral stenosis, are given. 
The average pulmonary blood volume in normal persons was $211 \mathrm{ml} . / \mathrm{m}^{2}$, in patients with mitral regurgitation $266 \mathrm{ml} . / \mathrm{m}^{2}$, and in those with mitral stenosis $419 \mathrm{ml} . / \mathrm{m}^{2}$

In patients with mitral stenosis the pulmonary blood volume could be related to pulmonary symptoms like exertional dyspnoea, haemoptysis, and paroxysmal nocturnal dyspnoea. Pulmonary blood volume could also be related directly to left atrial and pulmonary arterial pressures and inversely to pulmonary vascular resistance.

It is suggested that estimation of pulmonary blood volume may be an additional useful parameter to explain pulmonary symptoms of patients with mitral stenosis.

\section{REFERENCES}

Arnott, W. M. (1963). Brit. med. F., 2, 765.

Brockenbrough, E. C., and Braunwald, E. (1960). Amer. f. Cardiol., 6, 1062 .
Dock, D. S., Kraus, W. L., McGuire, L. B., Hyland, J. W., Haynes, F. W., and Dexter, L. (1961). \%. clin. Invest., 40, 317.

Eich, R. H., Chaffee, W. R., and Chodos, R. B. (1961). Circulat. Res., 9, 626.

Hamilton, W. F., Moore, J. W., Kinsman, J. M., and Spurling, R. G. (1932). Amer. F. Physiol., 99, 534.

Lagerlöf, H., Werkö, L., Bucht, H., and Holmgren, A. (1949). Scand. 7. clin. Lab. Invest., 1, 114.

McGaff, C. J., Roveti, G. C., Glassman, E., and Milnor, W. R. (1963) Circulation, 27, 77.

Milnor, W. R., Jose, A. D., and McGaff, C. J. (1960). Ibid., 22, 130.

New York Heart Association (1953). Nomenclature and Criteria for Diagnosis of Diseases of the Heart and Blood Vessels, 5th ed. N.Y.H.A., New York.

Roy, S. B., Bhatia, M. L., and Guleria, J. S. (1963). Indian Heart f., 15 255

- Gadboys, H. L., and Dow, J. W. (1957). Amer. Heart f., 54, 753.

Schreiner, B. F., Murphy, G. W., Glick, G., and Yu, P. N. (1963) Circulation, 27, 559.

Yu, P. N., Glick, G., Schreiner, B. F., and Murphy, G. W. (1963). Ibid., $27,541$.

\title{
Erythema Nodosum and Psittacosis : Report of Five Cases
}

\author{
MARTIN SARNER,* M.B., M.R.C.P. ; R. J. WILSON, $\dagger$ M.B., CH.B., B.SC., M.R.C.P., M.R.C.P.ED.
}

Brit. med. F., 1965, 2, 1469-1470

The list of aetiological agents alleged to provoke erythema nodosum is a long one, and the frequency with which different factors have been recorded varies with country, climate, age distribution of the examined community, and the collectors' particular interest. In the relatively unselected series reported by Vesey and Wilkinson (1959) 25 (36\%) of 70 cases had a proved or presumed streptococcal infection, 25 (36\%) had either bilateral hilar lymphadenopathy or sarcoidosis, and only four cases had tuberculosis. In Great Britain, once streptococcal sensitization, sarcoidosis, and tuberculosis have been excluded, an aetiological diagnosis is not often made, although an unusual provoking agent may be discovered under epidemic conditions. Erythema nodosum occurring in coccidiomycosis was first described in this way (Dickson, 1937).

We report here five cases of typical erythema nodosum which occurred in patients believed to be suffering from psittacosis acquired during an epidemic of this disease in East Anglia (Barrett and Greenberg, 1964). In every case the rash was erythematous, nodose, multiple, tender, symmetrical, and confined to the extensor surfaces of the limbs, and it faded through a spectrum of colours like that of a bruise.

\section{Case 1}

A woman aged 44 was admitted to hospital on 14 June 1964 with a history of rash on the arms and legs and a productive cough coming on a few days after a sore throat. There was no known contact with birds and she had not taken medicine of any sort prior to the onset of the rash. On examination she had extensive and typical erythema nodosum on the legs and a rash resembling erythema multiforme on the arms. There were no other abnormal physical signs.

Investigations showed : haemoglobin $11.1 \mathrm{~g} .100 \mathrm{ml}$.; W.B.C. 7,500/c.mm.; E.S.R. $95 \mathrm{~mm}$. in the first hour (Westergren) Sputum micrescopy showed pus cells, but only commensal organisms were isolated on culture. No acid-fast bacilli were seen or cultured, and the Mantoux reaction to $1 / 10,000$ and $1 / 1,000$ was negative.

\footnotetext{
* Late Medical Registrar, Addenbrooke's Hospital, Cambridge. Now
} t Senior Medical Registrar, Addenbrooke's Hospital, Cambridge.
Chest $x$-ray examination on admission showed nothing abnormal. A complement-fixation test for psittacosis on 18 June (two and a half weeks after onset of the illness) was positive at a titre of $1 / 512$. Complement-fixation tests for $\mathrm{Q}$ fever, adenovirus, and Eaton agent were all negative at less than 1/8. Antistreptolysin titre on 23 June was 330 Todd units $/ \mathrm{ml}$. Biopsy of a nodose lesion showed changes typical of erythema nodosum (Dr. J. Rack).

The patient subsequently developed a transient arthralgia with pyrexia, and an area of coarse crepitations at the left lung base. This rapidly settled on symptomatic treatment only, and she was discharged two weeks later, her erythema nodosum having faded very considerably. At a follow-up examination the chest $x$-ray picture was normal, E.S.R. was $14 \mathrm{~mm}$./hr., Mantoux to $1 / 100$ was negative, and the psittacosis titre had fallen to $1 / 64$.

\section{Case 2}

A woman aged 43 was admitted with a five-day history of general malaise followed by a rash on the arms and legs and a productive cough. She had taken four tablets of Drinamyl (amylobarbitone with dexamphetamine) for malaise about 48 hours prior to development of the rash. She was admitted on 5 June 1964 and found to have severe and typical erythema nodosum on the extensor surfaces of the arms and legs. There were crepitations at the left lung base but no other abnormal physical signs.

Investigations showed: haemoglobin $13 \mathrm{~g} .100 \mathrm{ml}$; W.B.C. $20,000 /$ c.mm. ( $86 \%$ neutrophil polymorphs); E.S.R. $105 \mathrm{~mm}$. in the first hour (Westergren). Sputum contained pus cells, but no pathogens were isolated on culture. Microscopical examination and culture for acid-fast bacilli proved to be negative on three occasions. Only commensal organisms were cultured from a throat swab. Chest $x$-ray examination showed dense consolidation involving the apical segment of the left lower lobe. Mantoux 1/1,000 was negative. A complement-fixation test for psittacosis on the day prior to admission was $1 / 32 ; 12$ days later it had risen to $1 / 256$. Complement-fixation tests for influenza $\mathrm{A}$ and $\mathrm{B}, \mathrm{Q}$ fever, adenovirus, and Eaton agent were all less than $1 / 8$ on two occasions. Antistreptolysin titre was 100 Todd units $/ \mathrm{ml}$. on two occasions.

Treatment with penicillin and subsequently ampicillin brought improvement, the erythema nodosum fading within 10 days. The chest $x$-ray picture five weeks later was normal and the complementfixation titre to psittacosis was $1 / 512$. 